\title{
Do networking centres perform better? An exploratory analysis in Psychiatry and Gastroenterology/Hepatology in Spain
}

\author{
Fernanda Morillo (1, 2), Adrián A. Díaz-Faes (1), Borja González-Albo (1) \& Luz Moreno (1) \\ (1) Instituto de Estudios Documentales sobre Ciencia y Tecnología (IEDCYT). \\ Centre for Human and Social Sciences (CCHS). Spanish National Research \\ Council (CSIC). \\ (2) Corresponding author: IEDCYT-CCHS, CSIC. Albasanz 26-28, 28037 Madrid \\ (Spain). Tel.: +34 916022881 . \\ E-mail addresses: fernanda.morillo@cchs.csic.es, adrian.arias@cchs.csic.es, \\ borja.gonzalezalbo@cchs.csic.es, luz.moreno@cchs.csic.es
}

\begin{abstract}
Science has become progressively more complex, requiring greater integration and collaboration between individuals, institutions and areas. Networking research establishes common rules and offers a suitable framework for this cooperation. Therefore, it is a good choice for both scientists and policy-makers. The objective of this study is to know whether the scientists perform better within these structures than outside them. As an example, we analysed the Biomedical Research Networking Centres in Spain and, for the exploratory investigation, we selected two disciplines (Psychiatry and Gastroenterology/Hepatology). The results showed that in every situation of networking research there were higher collaboration and impact rates. Furthermore, the main differences found between disciplines were related to the scope of cooperation, carried out at a more local level in Gastroenterology/Hepatology. Besides, HJ-Biplot technique allowed us to conclude that the outcomes may vary somewhat depending on the types of centres where the scientists work. Although further investigation is needed, the findings of this study might anticipate possible scenarios in which networking research could be the most natural way of collaboration.
\end{abstract}

\section{Keywords}

Networking centres; Research performance; Collaboration; Impact; HJ-Biplot; Psychiatry; Gastroenterology / Hepatology.

\section{Introduction}

Scientific research collaboration has grown outstandingly throughout the years, not only at the level of individuals, but also at the level of institutions and countries. Nowadays, it is considered that cooperation is vital for the development of any kind of research and therefore it should be encouraged and promoted by funding bodies and policy-makers. Increasing globalisation and change in research structure are leading to the development of a global community, placing the emphasis on collaboration and on the group rather than on competition and individuality. Physical location is no longer a barrier to the free exchange of information. The advantages of cooperation include the synergy among researchers, the risk reduction (it is possible to deal with several projects with greater chance of success), or the accuracy (high error detection). The disadvantages 
This is a postprint version of:

Morillo, F.; Díaz-Faes, A. A; González-Albo, B. \& Moreno, L. (2014). Do networking centres perform better? An

exploratory analysis in Psychiatry and Gastroenterology/Hepatology in Spain. Scientometrics, 98 (2), $1401-1416$.

The final publication is available at Springer via http://dx.doi.org/10.1007/s11192-013-1183-5

include the loss of individual visibility, the need to spend more time in management, or the discouragement of smaller competitors (Beaver, 2001; Breschi \& Cusmano, 2004). Due to the importance of research collaboration, several studies have attempted to quantify this concept. Most of them study the cooperation through co-authorship reflected in papers (Franceschet \& Costantini, 2010), although part of the collaboration is not included in formal communication and some contributions are not acknowledged (Laudel, 2002). Nevertheless, this analysis is a reasonable approach to study this phenomenon and allow us to explore some important aspects of the cooperative process (Bordons \& Gómez, 2000).

As for this process, it does not affect equally to all disciplines and actors. How important collaboration is and how it is carried out vary widely, depending on the type of research (basic or applied, international or local) (Abramo et al., 2011a). It is essential in the case of translational research areas, which are characterised by a combination of basic and applied science or by the transfer of outputs from basic science to practical applications in a faster and more efficient way (Woolf, 2008). Although differences with traditional research are very subtle, translational research is responsible for its own science, creating knowledge with a specific purpose and carrying it through an end. This type of research demands strong scientific cooperation and it is the reason behind the Biomedical Research Networking Centres (CIBER) in Spain. As stated in their website ${ }^{1}$, they are permanent collaborative research structures, supported by specific funding, in order to increase the critical mass and the excellence of research in a particular topic. Up to now, there are nine consortia formed through the association of research teams, from different centres, linked to the Spanish National Health System and focused in priority areas of the National $R+D+I$ Plan.

Apart from the CIBER structures, there are other types of "networking centres", which are groups of teams from different institutions working together. With this kind of networks, the goal is the creation of collaboration research schemes that can achieve ambitious objectives hardly accomplished in restricted performing contexts and that can have a greater impact in solving the problems of health or social nature (Valderrama-Zurián et al., 2007; Delgado Rodríguez, 2012). All of these structures help to maintain high competitiveness levels on the international framework, where future about health and economic leadership is debated. Besides, they have significantly changed the organisation and management of research, and they play a key role in the promotion of excellence (Font et al., 2008). Networking research is the ideal context for the development of a scientific programme in cooperation. Through this practice, researchers have the opportunity to work together in a common framework, to complement their scientific capabilities and to approach topics from different contexts.

Breschi \& Cusmano (2004) state that crucial "nodes" and networking research are increasingly fostered by the European Union funding programmes, with a special interest in the stimulation of high quality actors. It is believed that these "networks of excellence" will serve to overcome the fragmentation of the research system and will be able to reinforce the status in specific areas, considering that those centres of excellence already exist, but they are scattered and only loosely connected. In Spain, there are several general studies on the reason for the creation of CIBER and

\footnotetext{
${ }^{1}$ http://www.eng.isciii.es/ISCIII/es/contenidos/fd-investigacion/fd-ejecucion/fd-centros-participados/fdconsorcios2/cibers.shtml
} 
This is a postprint version of:

Morillo, F.; Díaz-Faes, A. A; González-Albo, B. \& Moreno, L. (2014). Do networking centres perform better? An

exploratory analysis in Psychiatry and Gastroenterology/Hepatology in Spain. Scientometrics, 98 (2), 1401-1416.

The final publication is available at Springer via http://dx.doi.org/10.1007/s11192-013-1183-5

some about the success obtained by a particular consortium. The work of Méndez Vásquez et al. (2009) analyses the Epidemiology and Public Health Centre (CIBERESP) and offers a detailed identification of authors and teams and their scientific production in the context of their discipline. On the other hand, there are also some studies exploring other networking organisations. The Cooperative Environment and Childhood Research Network was funded by the Spanish Ministry of Health, integrating different multidisciplinary research teams, to study effects of environment and diet on foetal and early childhood development in different geographical areas of the country (Fernández et al., 2007). Outside Spain, we can find medicine networks in other countries or group of countries, as in the case of the European Clinical Research Infrastructure Network (ECRIN), which is a consortium of eight networks in six countries. It is believed that ECRIN can be an advantageous framework for developing multinational projects in cross cutting domains and fostering collaboration among centres of excellence and highly qualified scientists (Demotes-Mainard \& Ohmann, 2005). In Canada, past experiences of networking research achieved already a great success. The Canadian Networks of Centres of Excellence program was created to address limitations in the Canadian research scene, linking researchers at universities across the country to work on joint projects (Rank \& Williams, 1999). Other examples can be placed in the USA, like the National Science Foundation Biology Directorate, which established the Research Coordination Network to promote the cooperation and development of research lines across disciplinary, geographical and organisational boundaries (Garner et al., 2012).

CIBER represent a good example of networking research and can help us to understand this kind of collaboration. Our main goal is to study and assess their scientific performance, and determine whether these stable structures obtain better results than the non-network centres. We want to contrast between the publication profiles with and without CIBER contributions, focusing the study in two disciplines. Within this exploratory analysis, we want to know if CIBER structures improve the efficiency and to find it out we pose some questions: Is there a stronger research impact? Is there a greater cooperation? Are there any differences between the two disciplines?

\section{Material and methods}

In this article, we used the Web of Science databases (WoS), years 2008-2011, in order to study the output of the Spanish and CIBER centres. For the correct identification of institutions, we had the aid of an automatic application previously developed. This application analysed detailed institutional data taking advantage of various master lists and giving optional codes to each address (Morillo et al., 2013). However, it was necessary a manual revision for the allocation of those records not completely assigned to a specific code. For this detailed study, we selected two WoS disciplines (Psychiatry and Gastroenterology/Hepatology) that best represented two CIBER consortia: Mental Health Centre (CIBERSAM), and Hepatic \& Digestive Diseases Centre (CIBEREHD).

Firstly, we offer a general overview of the CIBER output as compared to the Spanish one, showing the number of articles, the percentages of contributions and the relative indicators: the relative citation rate, the relative non-citation rate and the relative impact factor. Secondly, in each selected discipline, we divided all the Spanish output in two different sets, with and without CIBER contributions (as included in the address field). In each group, for each centre, we studied the number of articles, the percentages of cooperation (non-collaboration, only national, only 
This is a postprint version of:

Morillo, F.; Díaz-Faes, A. A; González-Albo, B. \& Moreno, L. (2014). Do networking centres perform better? An

exploratory analysis in Psychiatry and Gastroenterology/Hepatology in Spain. Scientometrics, 98 (2), 1401-1416.

The final publication is available at Springer via http://dx.doi.org/10.1007/s11192-013-1183-5

international and national \& international), the average number of authors, the average citations, the percentage of non-cited articles, the average impact factor, the average normalised position ${ }^{2}$ and the percentage of articles in the first quartile. Thirdly, we compared the CIBER sets of both disciplines excluding two variables: the average impact factor and the average citations. For the second and third analyses, we focused the study on the centres with a minimum number of publications (four or more articles in each group) to select only those ones specialised in the discipline. Finally, we applied a Kolmogorov-Smirnov test, since most of the variables were not normally distributed.

As well as the non-parametric tests, we also applied a multivariate analytical method, known as $\mathrm{HJ}$ Biplot. We selected the most relevant variables for this approach, and therefore we excluded the number of articles, the percentage of non-collaboration, the average citations and the average normalised position. Nevertheless, for the comparison between disciplines, we used the average normalised position instead of the average impact factor. The analysis was carried out through the software MultBiplot (Vicente-Villardón, 2010).

\section{$2.1 \quad H J$-Biplot method}

The HJ-Biplot (Galindo, 1986), an extension of the classical biplots introduced by Gabriel (1971), is an exploratory technique for discovering hidden patterns in a data matrix. This technique provides a joint representation of rows and columns in a low-dimensional space, using markers (points/vectors) for each of them. The markers are obtained by the usual singular value decomposition (SVD) of the data matrix. HJ-Biplot provides an optimum quality of representation for points and vectors, in the same reference system. Hence, it is possible to understand not only their positions, but also their relations. The rules for the interpretation of the HJ-Biplot are: 1) The distances between points (centres) are interpreted as an inverse function of similarities, in such a way that closer centres are more similar. 2) The lengths of the vectors (variables) approximate their standard deviations. 3) The cosines of the angles between the variables approximate the correlations between them in such a way that small acute angles are associated with high positive correlations, obtuse angles with high negative correlations and right angles with non-correlated variables. Likewise, the cosines of the angles between the variables and the axes (Principal Components) approximate the correlations between them. 4) The order of the orthogonal projections of the centres onto a variable approximates the order of the centres in that variable. The larger the projection of a centre onto a variable, the more this centre deviates from the average of that variable.

Furthermore, some additional measures can be employed as an aid to the correct interpretation (Galindo, 1986). For example, the squared correlation coefficient between a variable and a factor is defined as the relative contribution of the factor to the variance of the variable. As factors obtained are uncorrelated, the variance of a variable explained on a plane is the sum of the contributions to the axes that form the plane, and that quantity is known as "Quality of Representation" (QLR). Therefore, only variables with high QLRs should be interpreted on a particular plane. Moreover, it is

\footnotetext{
${ }^{2}$ This indicator is calculated by subtracting from 1 the ratio between the position of a journal in a JCR discipline and the total number of journals in the discipline concerned.
} 
This is a postprint version of:

Morillo, F.; Díaz-Faes, A. A; González-Albo, B. \& Moreno, L. (2014). Do networking centres perform better? An

exploratory analysis in Psychiatry and Gastroenterology/Hepatology in Spain. Scientometrics, 98 (2), 1401-1416.

The final publication is available at Springer via $\underline{\mathrm{http}: / / \mathrm{dx} . \mathrm{doi} . \mathrm{org} / 10.1007 / \mathrm{s} 11192-013-1183-5}$

possible to get an analogous measure of the QLR for each centre, since it is well represented when most of its information is accounted for on the lower dimensional space. In this study, we convert the QLR on a scale of 0 to 1000 points and centres with QLR below to 400 points are not displayed on the factorial planes.

Finally, we selected the two CIBER sets in order to identify relevant groups based on their similar performance and determine possible differences between both disciplines. The distances between centres allow for the identification of clusters with similar profiles. In order to determine the number of clusters $(\mathrm{k}=3)$, we explored hierarchical clustering patterns and AIC / BIC algorithms with the biplot coordinates. Then, we applied k-means clustering using the biplot scores and Euclidean distance as a measure. In this algorithm, the grouping is done by minimizing the sum of squared distances between items and the corresponding centroid of the cluster. The initial centroids were randomly chosen.

\section{Results}

\subsection{General results}

CIBER published 8,668 articles (10,907 documents) in the WoS databases, years $2008-2011$ (5\% of the whole output of Spain). This production was mainly devoted to the Clinical Medicine area (57\%) and there was a great tendency to cooperate inside large groups of authors (11 or more). Moreover, there was a higher level of collaboration (85\%) contrasted with the already outstanding cooperation of Spain (73\%). Overall, CIBER reached better values in all of the relative indicators: the relative citation rate ( $R C R)$, the relative non-citation rate (RNCR), and the relative impact factor (RIF). Clinical Medicine (in which Gastroenterology/Hepatology and Psychiatry are included) represented $13 \%$ of the Spanish documents in this area and achieved a RCR $26 \%$ higher, a RNCR $18 \%$ lower and a RIF 34\% higher than the Spanish averages. Table 1 shows the production and impact values obtained by CIBER versus Spain by WoS disciplines. While CIBER got better impact than Spain in Gastroenterology/Hepatology, CIBER publications yielded slightly better values in Psychiatry. Yet, both of them had the highest contributions to the Spanish scientific production.

Table 1 Production and impact of CIBER versus Spain by WoS disciplines (2008-2011)

\begin{tabular}{lcccccc}
\hline \multirow{2}{*}{ Discipline } & \multicolumn{3}{c}{ ClBER } & \multicolumn{3}{c}{ Relative Indicators CIBER / Spain } \\
\cline { 2 - 7 } & Art & $\%$ & RCR & RNCR & RIF & $\begin{array}{c}\text { \%CIBER } \\
\text { contribution }\end{array}$ \\
\hline Neurosciences & 810 & 9.34 & 1.11 & 0.89 & 1.15 & 18.30 \\
Biochemistry \& Molecular Biology & 774 & 8.93 & 1.04 & 1.06 & 1.15 & 11.72 \\
Psychiatry & 636 & 7.34 & 1.05 & 1.03 & 1.19 & $\mathbf{3 3 . 1 1}$ \\
Gastroenterology \& Hepatology & 634 & 7.31 & $\mathbf{1 . 3 4}$ & 0.80 & $\mathbf{1 . 3 5}$ & $\mathbf{3 5 . 9 6}$ \\
Clinical Neurology & 585 & 6.75 & 1.30 & 0.89 & 1.32 & 18.04 \\
Endocrinology \& Metabolism & 584 & 6.74 & 0.99 & 0.98 & 1.17 & 28.23 \\
Genetics \& Heredity & 550 & 6.35 & 1.08 & 1.06 & 1.25 & 18.16 \\
Pharmacology \& Pharmacy & 546 & 6.30 & 1.31 & $\mathbf{0 . 7 6}$ & 1.23 & 12.62 \\
Public, Environmental \& Occupational Health & 448 & 5.17 & $\mathbf{1 . 4 6}$ & $\mathbf{0 . 7 3}$ & $\mathbf{1 . 4 3}$ & 18.62 \\
Cell Biology & 397 & 4.58 & 1.18 & 1.08 & 1.01 & 13.59 \\
Oncology & 320 & 3.69 & 0.95 & 0.82 & 1.02 & 9.21 \\
Respiratory System & 315 & 3.63 & 1.21 & 0.92 & 1.30 & 27.02 \\
\hline
\end{tabular}


This is a postprint version of:

Morillo, F.; Díaz-Faes, A. A; González-Albo, B. \& Moreno, L. (2014). Do networking centres perform better? An

exploratory analysis in Psychiatry and Gastroenterology/Hepatology in Spain. Scientometrics, 98 (2), 1401-1416.

The final publication is available at Springer via http://dx.doi.org/10.1007/s11192-013-1183-5

\begin{tabular}{lcccccrr}
\hline \multirow{2}{*}{ Discipline } & \multicolumn{3}{c}{ ClBER } & \multicolumn{4}{c}{ Relative Indicators CIBER / Spain } \\
\cline { 2 - 8 } & Art & $\%$ & RCR & RNCR & RIF & $\begin{array}{c}\text { \%CIBER } \\
\text { contribution }\end{array}$ \\
\hline Immunology & 298 & 3.44 & 0.94 & 0.97 & 1.14 & 9.08 \\
Nutrition \& Dietetics & 295 & 3.40 & 1.18 & 0.85 & 1.32 & 13.11 \\
Infectious Diseases & 287 & 3.31 & 1.05 & 0.96 & 1.06 & 12.24 \\
Microbiology & 285 & 3.29 & 1.07 & 0.87 & 1.19 & 7.01 \\
Multidisciplinary Sciences & 265 & 3.06 & 1.03 & 1.16 & 0.92 & 10.90 \\
\hline \%: Percentage calculated with respect to the total number of articles. RCR: relative citation rate; RNCR: relative non- \\
citation rate; RIF: relative impact factor.
\end{tabular}

In the exploratory analysis, we studied the two WoS disciplines proposed, years 2008-2011: Psychiatry (1,921 Spanish articles) and Gastroenterology/Hepatology (1,763 Spanish articles).

\subsection{Psychiatry}

We selected those centres publishing four or more articles in Psychiatry, with CIBER participation (85) or without it (134). In the CIBER set, almost $90 \%$ of the articles presented collaboration and $51 \%$ included international cooperation. The non-CIBER set had also a high collaboration (83\%) and a medium-low international cooperation (41\%), but it was lower than in the CIBER set in both cases. The Kolmogorov-Smirnov test presented significant differences between groups in all variables $(p<$ 0.05), though to a lesser extent in the percentage of non-cited articles. Conversely, the most notable dissimilarities were found in the expected impact variables (mainly in the average impact factor) and in the average number of authors. For the CIBER set, box plots showed better values in most of the variables, like those presented as examples in the Fig. 1.
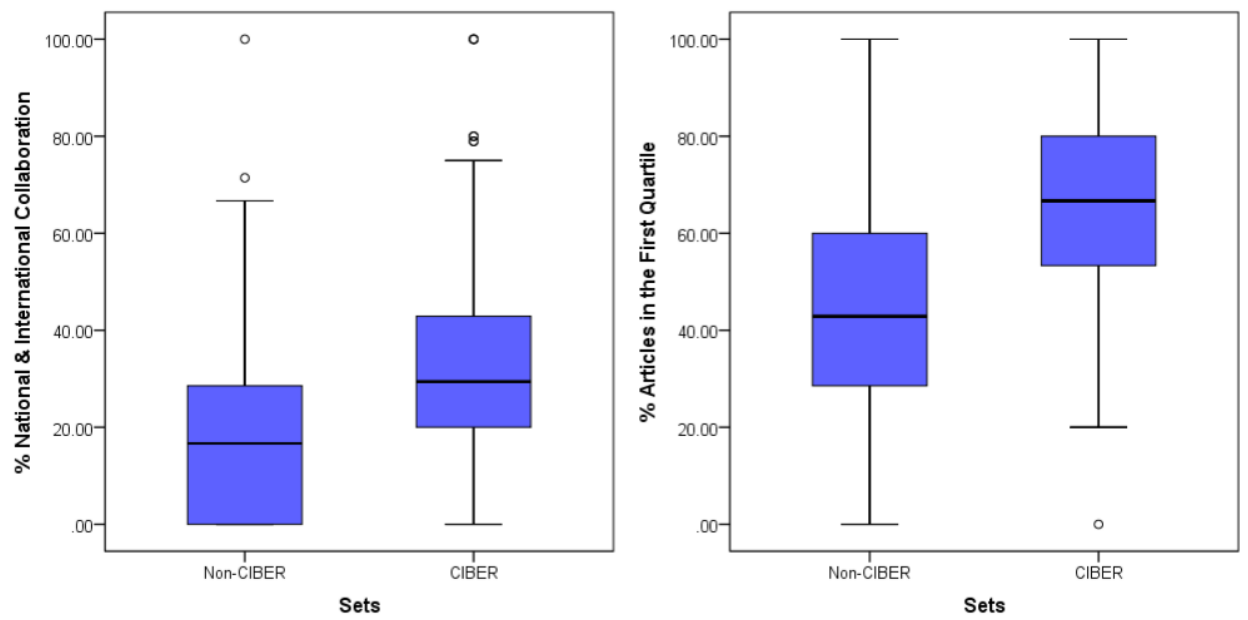

Fig. 1 Box plots comparing the two sets in Psychiatry (four or more articles)

HJ-Biplot was applied to a matrix with 219 centres and 7 variables (see 2 Material and methods). Only four axes explained $88.3 \%$ of the total inertia (variance), while the factorial plane 1-2 shown in Fig. 2 explained $60 \%$. Observing the relative contributions of the factor to the element for variables, we could interpret almost all the variables on the factorial plane 1-2, but to a lesser extent for the percentages of only international collaboration and non-cited articles. In the case of the percentage 
This is a postprint version of:

Morillo, F.; Díaz-Faes, A. A; González-Albo, B. \& Moreno, L. (2014). Do networking centres perform better? An

exploratory analysis in Psychiatry and Gastroenterology/Hepatology in Spain. Scientometrics, 98 (2), 1401-1416.

The final publication is available at Springer via $\underline{\mathrm{http}: / / \mathrm{dx} . \mathrm{doi} . \mathrm{org} / 10.1007 / \mathrm{s} 11192-013-1183-5}$

of national \& international cooperation, there was a better QLR for the factorial plane 1-3. The factorial plane 3-4 offered additional data related with the percentage of non-cited articles that mainly characterise a small set of CIBER centres, which showed a weak performance, while plane 2-3 presented supplementary information for only international collaboration for a small group of non-CIBER set (see Appendix, Table A 1). In the HJ-Biplot of the factorial plane 1-2 (Fig. 2), Axis 1 was chiefly characterised by the impact of publications (the average impact factor and the percentage of articles in the first quartile) and centres on one side of the plot reached the highest values (from the right to the left hand side). Moreover, as the impact of publications increases, there is a growth in the number of authors (acute angle between this variable and those of the impact), correlating to some extent with the percentage of national \& international collaboration. This mostly happened in the CIBER set (centres beginning with " $\mathrm{C}$ ") and those placed in the top right and in the bottom right quadrants belonged mainly to the non-CIBER group (centres beginning with "N"). These were characterised by a high percentage of only national cooperation, which was weakly related to Axis 2 .

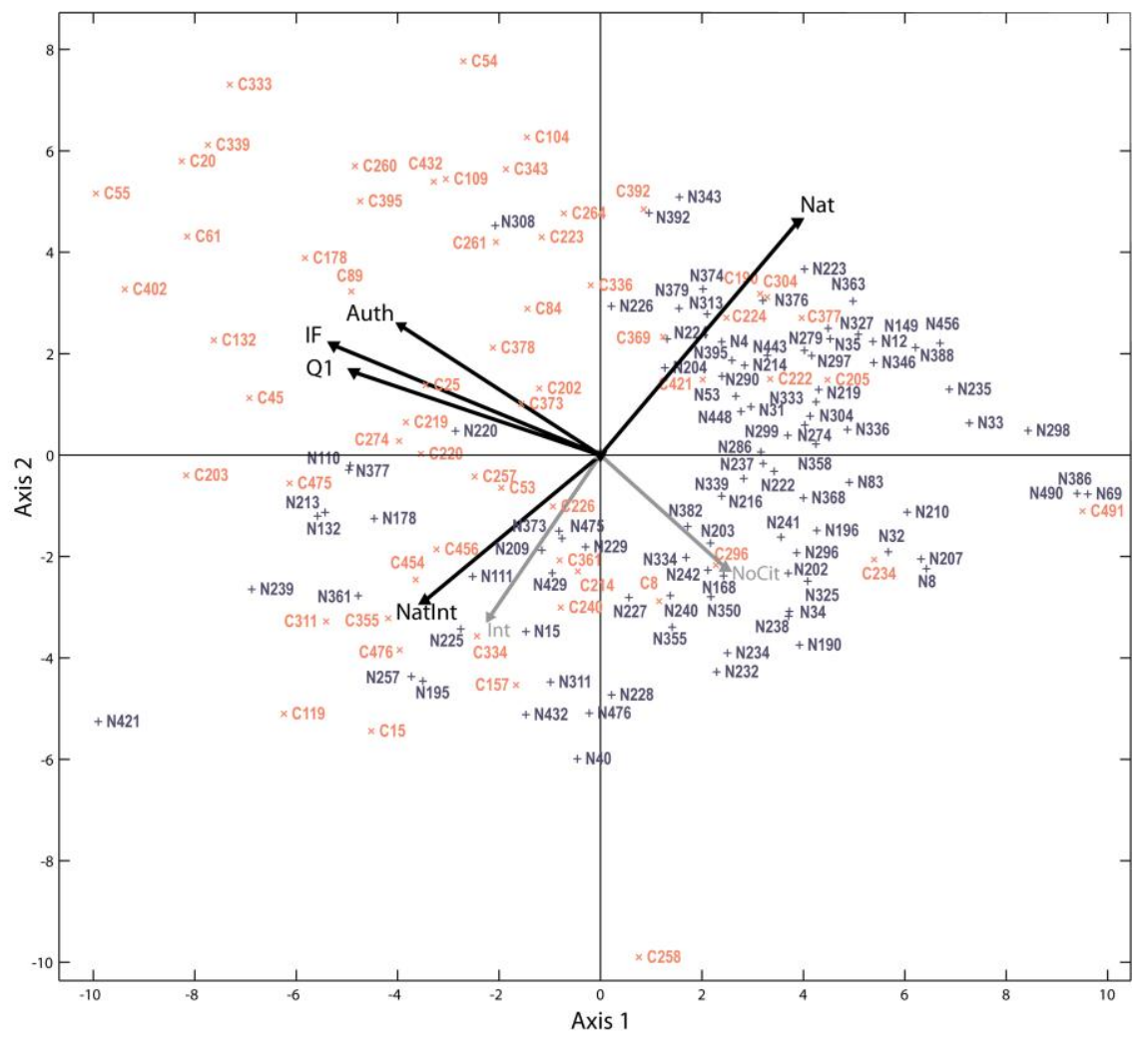

Fig. 2 Two-dimensional HJ-Biplot in Psychiatry for the two sets

Variables coloured in grey present a QLR below 400 points. CIBER set: centres beginning with "C". Non-CIBER set: centres beginning with "N". Int: percentage of only international collaboration. NatInt: percentage of national \& international collaboration. Nat: percentage of only national collaboration. Auth: average number of authors. NoCit: percentage of non-cited articles. IF: average impact factor. Q1: percentage of articles in the first quartile.

\subsection{Gastroenterology/Hepatology}

As in Psychiatry, we selected those centres publishing four or more articles in Gastroenterology/Hepatology, with CIBER participation (65) or without it (127). In the CIBER set, 
This is a postprint version of:

Morillo, F.; Díaz-Faes, A. A; González-Albo, B. \& Moreno, L. (2014). Do networking centres perform better? An

exploratory analysis in Psychiatry and Gastroenterology/Hepatology in Spain. Scientometrics, 98 (2), 1401-1416.

The final publication is available at Springer via $\underline{\mathrm{http}: / / \mathrm{dx} . \mathrm{doi} . \mathrm{org} / 10.1007 / \mathrm{s} 11192-013-1183-5}$

almost $79 \%$ of the articles presented collaboration and $34 \%$ included international cooperation. The non-CIBER set had also a similar high collaboration (75\%) with less representation of the international cooperation (24\%), but it was lower than in the CIBER set in both cases. After applying the Kolmogorov-Smirnov test, we found significant differences between groups $(p<0.05)$, except for the percentages of only international and only national cooperation. In contrast, the greatest dissimilarity was detected in the percentage of articles in the first quartile, followed by the average citations. For the CIBER set, box plots showed better values in most of the variables, like those presented as examples in the Fig. 3.
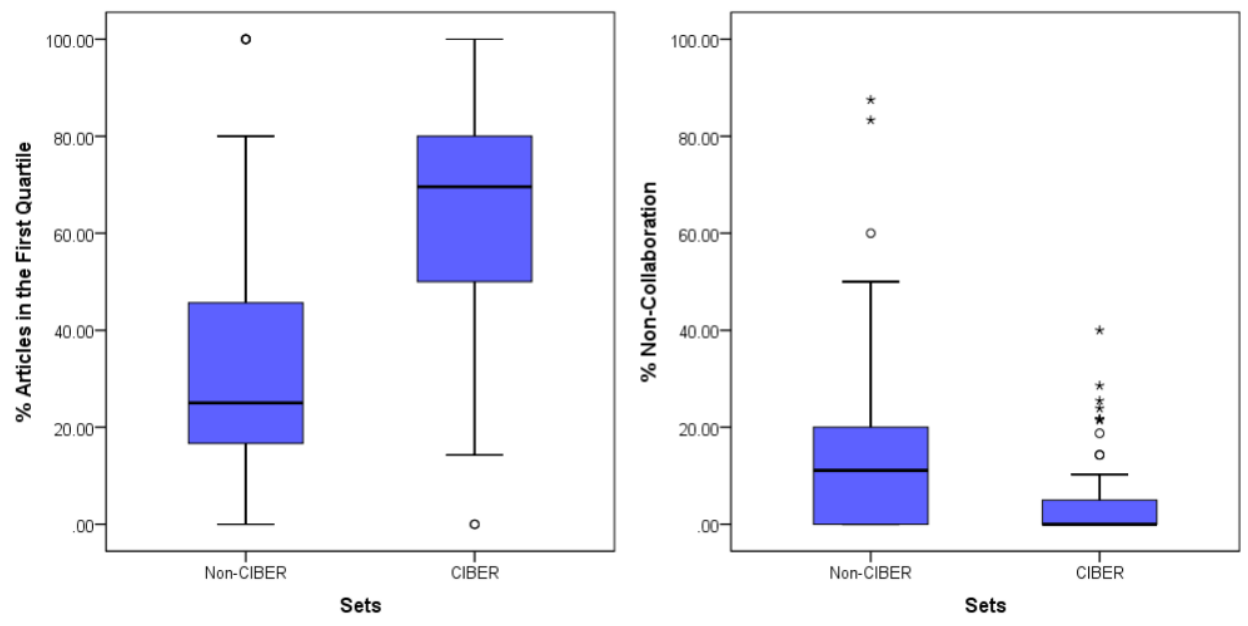

Fig. 3 Box plots comparing the two sets in Gastroenterology/Hepatology (four or more articles)

For the HJ-Biplot analysis, we worked with a matrix of 192 centres and 7 variables (see 2 Material and methods). Retaining four axes, the total explained inertia was almost $90 \%$, while the factorial plane 1-2 shown in Fig. 4 explained 66\%. Observing the relative contributions of the factor to the element for variables (see Appendix, Table A 2), we could interpret all the variables on the factorial plane 1-2, although for some variables QLR was better on other factorial planes. In this sense, the plane 2-4 offered additional information about the average number of authors characterising a small group of CIBER set with a large number of authors and a high only national collaboration. Furthermore, the plane 1-3 showed a better representation of the percentage of national \& international collaboration. In the plane 1-2 (Fig. 4), Axis 1 was mainly described by data regarding the impact of publications, the percentage of national \& international collaboration and the percentage of non-cited articles (from the right to the left hand side). Axis 2 was mostly represented by the percentage of only international collaboration (centres at the top of the plot) and the percentage of only national cooperation (centres at the bottom). Taking into account the variables, the average number of authors and the percentage of national \& international collaboration were directly correlated with the impact variables (acute angles) and all of them inversely correlated with the percentage of non-cited articles (obtuse angles). Overall, the pattern of the centres in Gastroenterology/Hepatology seemed slightly heterogeneous between groups. Nevertheless, CIBER set was characterised by publications in high impact journals, with a great number of authors and a high percentage of national \& international cooperation, while non-CIBER 
This is a postprint version of:

Morillo, F.; Díaz-Faes, A. A; González-Albo, B. \& Moreno, L. (2014). Do networking centres perform better? An

exploratory analysis in Psychiatry and Gastroenterology/Hepatology in Spain. Scientometrics, 98 (2), 1401-1416.

The final publication is available at Springer via http://dx.doi.org/10.1007/s11192-013-1183-5

set was defined by significant percentages of only international or only national collaboration. Besides, in this group there was an important number of centres with a poor performance.

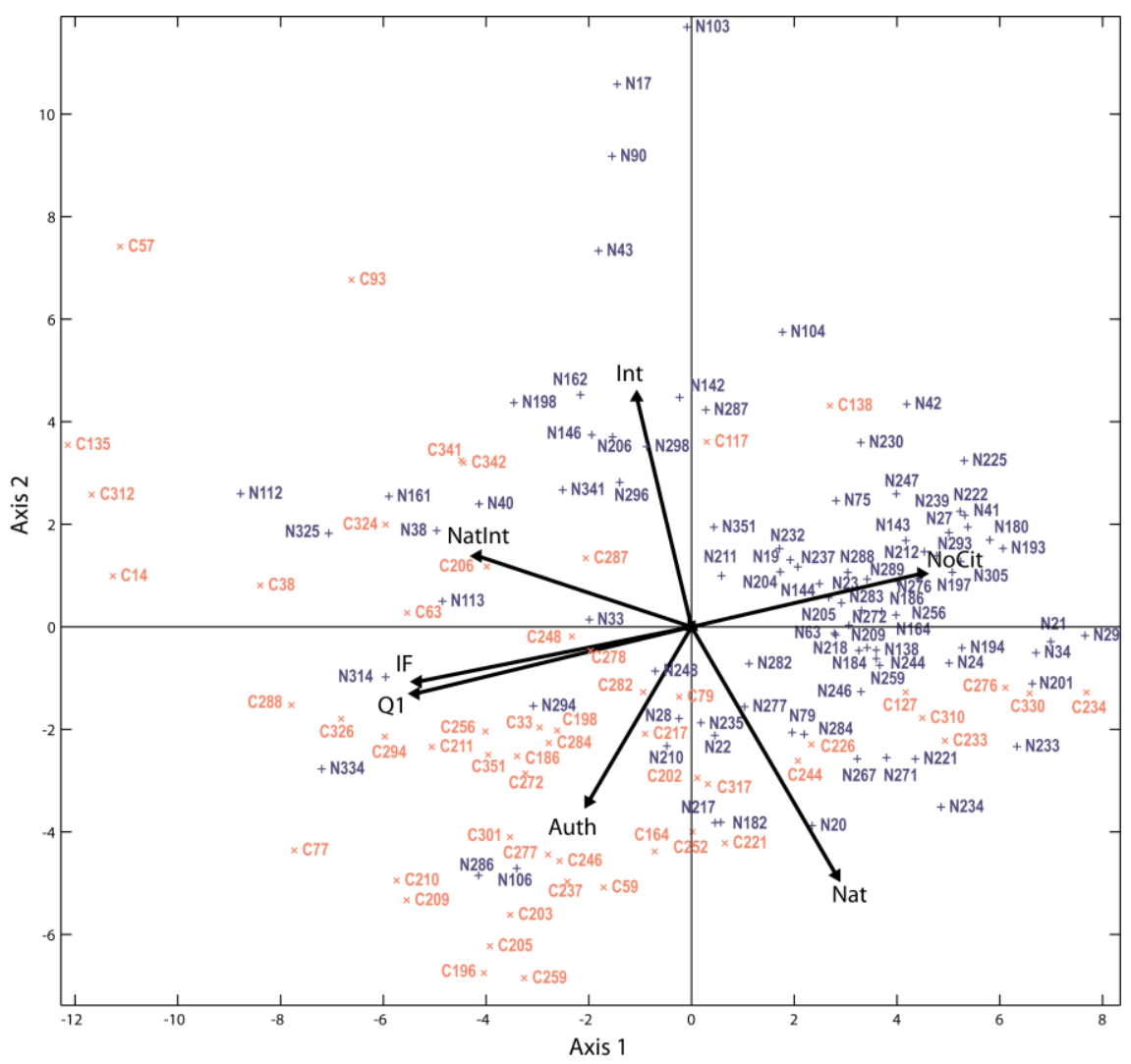

Fig. 4 Two-dimensional HJ-Biplot in Gastroenterology/Hepatology for the two sets

CIBER set: centres beginning with "C". Non-CIBER set: centres beginning with " $\mathrm{N}$ ". Int: percentage of only international collaboration; NatInt: percentage of national \& international collaboration; Nat: percentage of only national collaboration; Auth: average number of authors; NoCit: percentage of non-cited articles; IF: average impact factor; Q1: percentage of articles in the first quartile.

\subsection{Psychiatry versus Gastroenterology/Hepatology}

To study differences between both disciplines, we made a comparison of the CIBER sets (85 Psychiatry centres versus 65 Gastroenterology/Hepatology centres). As we stated before, the CIBER set had higher collaboration in the first discipline (90\%) than in Gastroenterology/Hepatology (79\%), and presented an outstanding international cooperation (51\%) as compared to the one in the other discipline (34\%). However, the CIBER set obtained in Gastroenterology/Hepatology a higher only national collaboration percentage (44\%) than in Psychiatry (39\%). The KolmogorovSmirnov test revealed significant differences between groups in most of the variables $(p<0.05)$, apart from the percentage of only international cooperation. Nevertheless, distributions were very similar, except for the national \& international collaboration and the percentage of non-cited articles.

Regarding the HJ-Biplot in Psychiatry (Fig. 5), Axis 1 was characterised by the variables of the impact and the average number of authors. On the other hand, Axis 2 contained information on the 
This is a postprint version of:

Morillo, F.; Díaz-Faes, A. A; González-Albo, B. \& Moreno, L. (2014). Do networking centres perform better? An

exploratory analysis in Psychiatry and Gastroenterology/Hepatology in Spain. Scientometrics, 98 (2), 1401-1416.

The final publication is available at Springer via $\underline{\mathrm{http}: / / \mathrm{dx} . \mathrm{doi} . \mathrm{org} / 10.1007 / \mathrm{s} 11192-013-1183-5}$

percentages of national \& international and only national cooperation (see Appendix, Table A 3). We found three clearly defined clusters:

- Cluster 1 (47\% of the centres) presented the best research output with a high percentage of articles in the first quartile, large number of authors and high collaboration rates, mainly national oriented with some international links. Those more national \& international oriented reached higher impact. In addition, they also showed a high average normalised position.

- Cluster 2 included centres (27\% of the total) with high rates of publication in national \& international cooperation, and with some only international relations, although this last variable was better represented by the Axis 3 . Nevertheless, these centres received fewer citations.

- Cluster 3 gathered the smallest collection (26\% of the centres) and was associated with a pattern of mostly national collaboration. Comparing with the other clusters, these centres were the least cited ones and showed the weakest performance in terms of impact (average normalised position and percentage of articles in the first quartile).

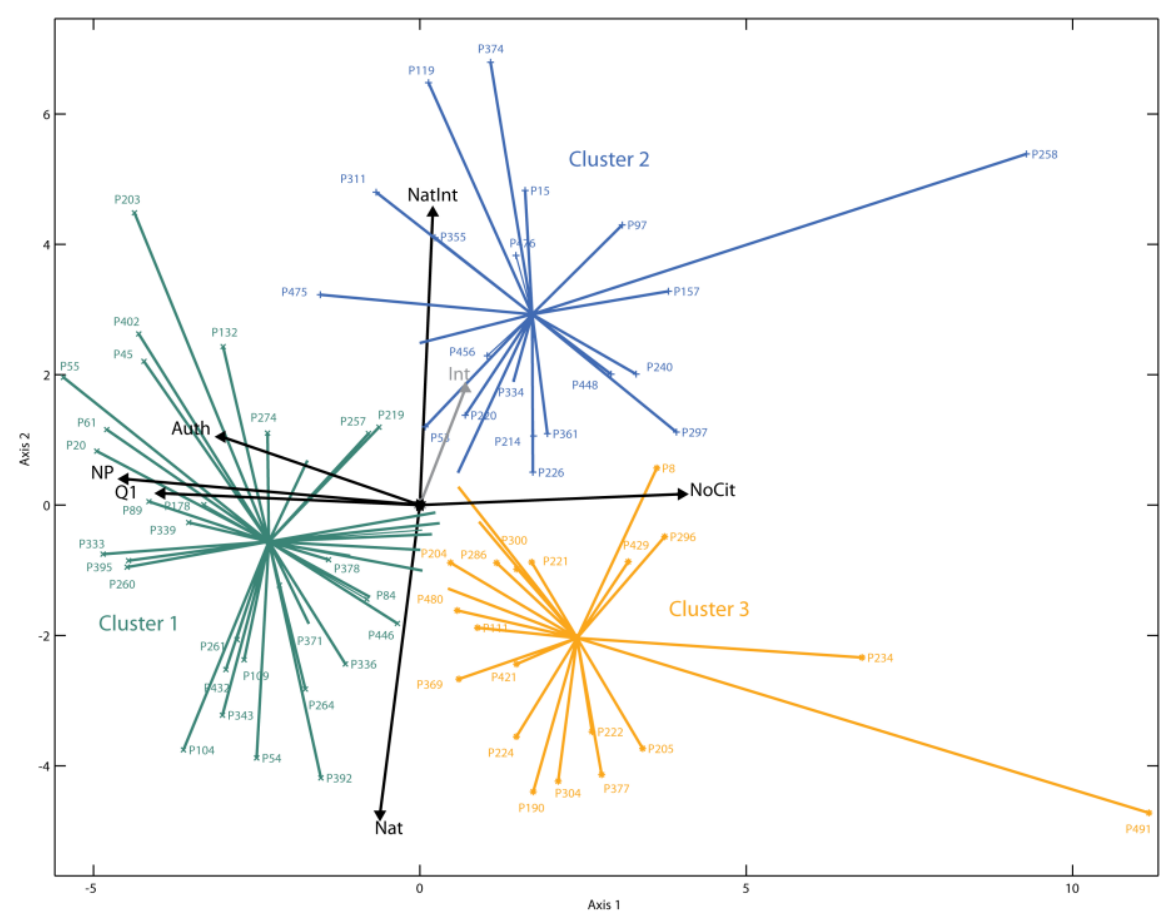

Fig. 5 Clusters in the two-dimensional HJ-Biplot for the CIBER set in Psychiatry

Int: percentage of only international collaboration; NatInt: percentage of national \& international collaboration; Nat: percentage of only national collaboration; Auth: average number of authors; NoCit: percentage of non-cited articles; NP: average normalised position; Q1: percentage of articles in the first quartile.

For Gastroenterology/Hepatology centres (Fig. 6), all variables had good QLR on the plane 1-2. Impact variables discriminated better in Axis 1, while Axis 2 was characterised mainly by the average number of authors and the percentage of only international and only national cooperation (see Appendix, Table A 4). We identified three different groups: 
This is a postprint version of:

Morillo, F.; Díaz-Faes, A. A; González-Albo, B. \& Moreno, L. (2014). Do networking centres perform better? An

exploratory analysis in Psychiatry and Gastroenterology/Hepatology in Spain. Scientometrics, 98 (2), 1401-1416.

The final publication is available at Springer via http://dx.doi.org/10.1007/s11192-013-1183-5

- Cluster 1 ( $20 \%$ of the centres) contained outstanding values of impact and visibility, with high rates of national \& international collaboration, high rates of only international collaboration, high percentages of articles in the first quartile and a high average normalised position.

- Cluster 2 (40\% of the centres) was described by mainly national cooperation (with some international links), associated with a great number of authors and remarkable rates of impact and visibility, with high percentages of articles in the first quartile and a high average normalised position.

- Cluster 3 ( $40 \%$ of the centres) was associated with lower impact values and higher percentages of non-cited articles. Centres had both national and international links.

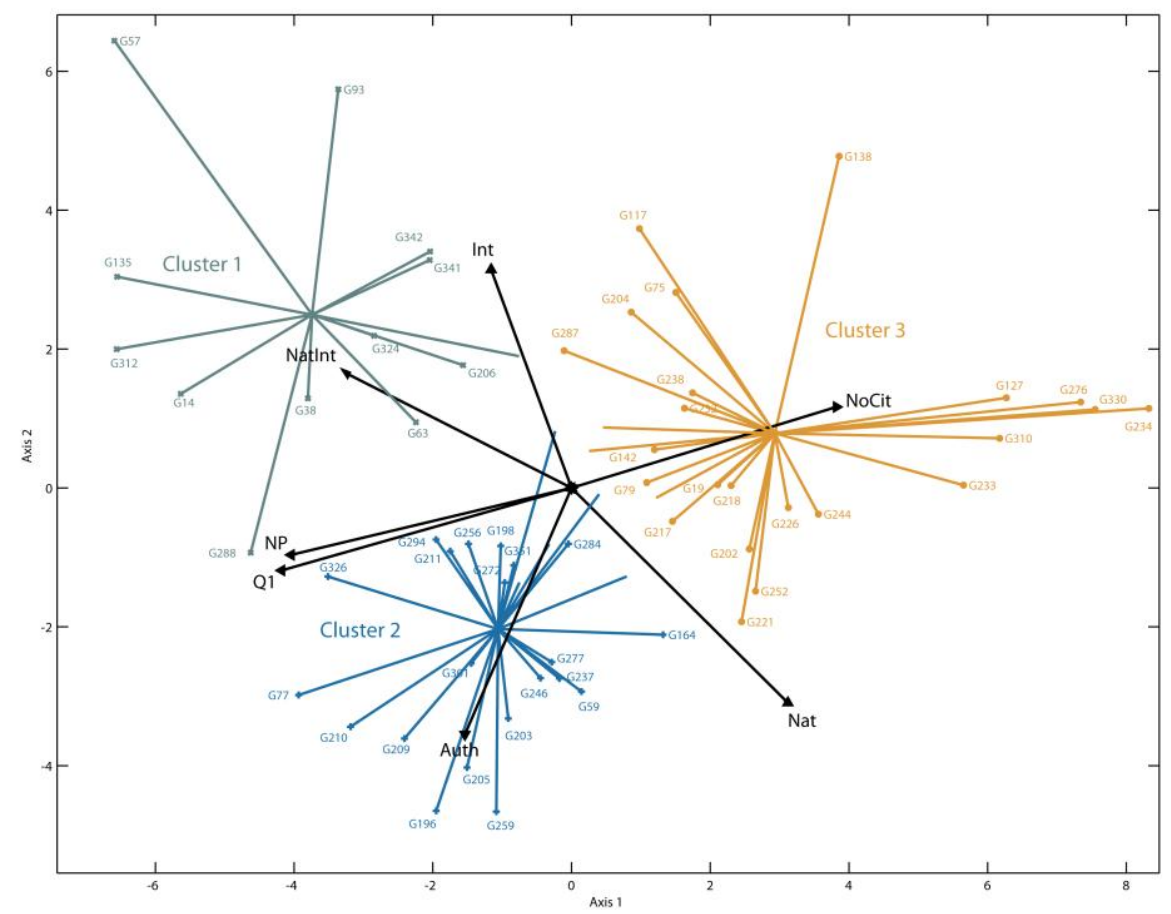

Fig. 6 Clusters in the two-dimensional HJ-Biplot for the CIBER set in Gastroenterology/Hepatology

Int: percentage of only international collaboration; NatInt: percentage of national \& international collaboration; Nat: percentage of only national collaboration; Auth: average number of authors; NoCit: percentage of non-cited articles; NP: average normalised position; Q1: percentage of articles in the first quartile.

\section{Discussion and conclusions}

The increasing specialisation of science has encouraged researchers to collaborate, which in turn allows them to reduce costs (Bordons \& Gómez, 2000). Moreover, a shared structure can make easier the work among research teams from different geographical or thematic areas, creating synergies and producing excellent results. Policy-makers know that they should undertake a major financial investment if they want to attain broad and better output. This is the reason why various bodies and public agencies are fostering networking research in different countries, inside and outside their territory, as this type of collaboration enables a less expensive performance of complex studies (Demotes-Mainard \& Ohmann, 2005). Some examples of this kind of association 
This is a postprint version of:

Morillo, F.; Díaz-Faes, A. A; González-Albo, B. \& Moreno, L. (2014). Do networking centres perform better? An

exploratory analysis in Psychiatry and Gastroenterology/Hepatology in Spain. Scientometrics, 98 (2), 1401-1416.

The final publication is available at Springer via http://dx.doi.org/10.1007/s11192-013-1183-5

yielded already outstanding outcomes, like the Canadian Network of Centres of Excellence (Rank \& Williams, 1999). They concluded that the cases examined obtained remarkable profits, because they were very proactive in searching out exploitation opportunities. Other networks showed even valuable outcomes for society, as in the case accounted for in Fanaroff et al. (2003), which contributed to a significant reduction in child mortality. Furthermore, recent studies offered also exceptional results as measured through bibliometric indicators. Garner et al. (2012) stated that the USA Research Coordination Network had a significant increase of collaboration and interdisciplinarity, with a higher productivity, greater impact and citation rates, and an important international visibility.

With this proposal, we wished to know if the Spanish centres performed better within networking structures than outside them, and to delve into this issue we selected the Biomedical Research Networking Centres (CIBER). Although several authors had studied some of these centres, we wanted to provide a new perspective focused on the type of research association. CIBER as a whole represented a relevant part of the Spanish output with higher contributions than the average (over 33\%) in Psychiatry and in Gastroenterology/Hepatology. Overall, CIBER obtained better results than the whole country, reaching remarkable values of impact and having a greater level of collaboration, mainly with a relevant national implication. This point was also sustained by the work of Delgado Rodriguez (2012), who stated that cooperation of CIBERESP increased from $9 \%$ to $16 \%$, as measured by the proportion of articles in which more than one team participated. Besides, he found that the impact measures tripled. These results were analogous to those offered by Méndez Vásquez et al. (2009) in a report of CIBERESP, where $53 \%$ of the teams achieved more citations than the Spanish average in the field.

In the exploratory analysis, a direct interpretation of results offered significant values for impact in the CIBER sets as much in Psychiatry as in Gastroenterology/Hepatology, as compared to those of the non-CIBER sets. In the plots, we observed for both disciplines that the national \& international collaboration presents a positive correlation with the impact variables and the average number of authors (acute angles between the variables), thanks to the homogeneous performance of the centres involved. Concerning the only national collaboration and the only international collaboration, in general there is no relation with the impact variables, because the performance of the centres involved is more heterogeneous. In the case of Psychiatry, we observed that the greater the average number of authors, the higher the impact. In addition, although to some extent, there were notable impacts for those centres with important percentages of national \& international collaboration. Considering Gastroenterology/Hepatology, although the pattern was slightly heterogeneous, the impact was striking again and related with a greater average number of authors, a higher percentage of cooperation and a lower percentage of non-cited articles. Given the excellent impact of CIBER sets in both disciplines, it was not surprising that their main divergences appeared in the non-cited articles and in the kind of collaboration, being Gastroenterology/Hepatology the discipline with a higher percentage of only national cooperation.

The usefulness of Biplots methods was proved in areas such as medicine, economics, biology or environmental technology (Cárdenas et al., 2007), while Díaz-Faes et al. (2011;2013) have stated its interest in bibliometrics. The application of HJ-Biplot enabled us to employ a multivariate approach from an integrated study of indicators, since it provides an optimum quality of 
This is a postprint version of:

Morillo, F.; Díaz-Faes, A. A; González-Albo, B. \& Moreno, L. (2014). Do networking centres perform better? An

exploratory analysis in Psychiatry and Gastroenterology/Hepatology in Spain. Scientometrics, 98 (2), 1401-1416.

The final publication is available at Springer via http://dx.doi.org/10.1007/s11192-013-1183-5

representation for rows and columns in the same reference system. Besides, this method allowed us to classify centres of the CIBER set considering the impact and cooperation of their scientific activity, identifying clearly the variables that explain the associations found. Two clusters in Psychiatry showed centres (around 50\%) with important percentages of non-cited articles, while two clusters in Gastroenterology/Hepatology included centres (60\%) with outstanding impact rates. Those clusters revealed some of the differences between both disciplines and, while international collaboration is usually related to wider visibility (see e.g. Ibáñez et al., 2013), in the case of Gastroenterology/Hepatology, we could appreciate that the greater the percentage of national cooperation the higher the impact, with or without international links. As Abramo et al. (2011b) indicated, although international collaboration generally attracts more documents, it is pertinent to examine specific situations. When we examine the individual behaviour of centres of the CIBER set in Psychiatry, we also observed that part of them had high only national collaboration percentages and high impact. In the case of Gastroenterology/Hepatology, centres with national collaboration obtained more impact as a whole than others do, although there is a striking cluster with high international collaboration and high impact.

The results of this work provide additional data, which support the idea that networking research centres yield better outputs. Liao (2011) also considered that higher levels of research quality could be reached with strong collaboration intensity. In other words, the more a scholar is embedded in his or her collaboration network, the higher the research quality. Garner et al. (2012) carried out a comparison between a group of researchers before and after receiving funding. We could not accomplish this contrast because of problems in identifying the research teams involved. However, we believe that the comparison between CIBER and non-CIBER sets provides enough information to come to the same conclusion as other studies. We not only offer an overview of the research carried out in this context, but we also study dissimilarities with non-networking centres and differences between disciplines. We can determine that these Spanish structures have similar characteristics to those of other countries, and particular features of each research topic explain the differences found, as it was stated in a previous study (Morillo \& Aparicio, 2011). The HJ-Biplot enables us to study these variances concluding that this kind of association produces synergies and outputs with higher levels of collaboration and impact. Moreover, thanks to the clusters obtained, we know that results may differ somewhat depending on the types of centres, which is very useful in guiding research policy and future investment decisions, because there is no research excellence without funding. Nevertheless, further investigation is needed to know if enhanced results are achieved only by a greater financial support, or if the type of research association also improves the quality of the output. The answer to this question might be found by examining the acknowledgment section of each publication, which usually includes information regarding funding.

Public agencies that are fostering this type of collaboration can consider that these structures are able to obtain better performance, promote synergies and produce remarkable results, widening research goals and diminishing errors. In this sense, we think that networking research can be the natural scenario in the next future, as it offers a stable framework and common rules. New information technologies allow data sharing and help to enhance cooperation perspectives. Since the latter is increasingly important in contrast to competition and individuality, new associations and partnerships have been tested and are being tested to study their feasibility and select the 
This is a postprint version of:

Morillo, F.; Díaz-Faes, A. A; González-Albo, B. \& Moreno, L. (2014). Do networking centres perform better? An

exploratory analysis in Psychiatry and Gastroenterology/Hepatology in Spain. Scientometrics, 98 (2), $1401-1416$.

The final publication is available at Springer via $\underline{\mathrm{http}: / / \mathrm{dx} . \mathrm{doi} . \mathrm{org} / 10.1007 / \mathrm{s} 11192-013-1183-5}$

most suitable structure for each type of research. Following this path, we want to continue analysing in depth other cooperative institutions in order to assess and contrast them.

\section{Acknowledgements}

This work is supported by the Spanish Ministry of Science and Innovation (Grant CSO2011-25102). Adrián A. Díaz-Faes is granted with a JAE predoctoral fellowship by the Spanish National Research Council (CSIC). We want to thank Purificación Galindo for her valuable suggestions about statistics methodology.

\section{References}

Abramo, G.; D’Angelo, C.A.; \& Solazzi, M. (2011a). Are researchers that collaborate more at the international level top performers? An investigation on the Italian university system. Journal of Informetrics, 5(1), 204213.

Abramo, G; D’Angelo, C.A. \& Solazzi, M. (2011b). The relationship between scientists' research performance and the degree of internationalization of their research. Scientometrics, 86(3), 629-643.

Beaver, D. deB. (2001). Reflections on scientific collaboration (and its study): past, present, and future. Scientometrics, 52(3), 365-377.

Bordons, M. \& Gómez, I. (2000). Collaboration Networks in Science. In: Cronin, B. \& Atkins, H. B. (editors). The Web of Knowledge. A Festschrift in Honor of Eugene Garfield. ASIS Monograph Series. Information Today, Inc. Medford, NJ, EE.UU.

Breschi, S. \& Cusmano, L. (2004). Unveiling the texture of a European Research Area: Emergence of oligarchic networks under EU framework programmes. International Journal of Technology Management, 27(8), 747-772.

Cárdenas, O.; Galindo, M.P. \& Vicente-Villardón, J.L. (2007). Los métodos Biplot: evolución y aplicaciones. Revista Venezolana de Análisis de Coyuntura, 13(1), 279-303.

Delgado Rodríguez, M. (2012). CIBERESP: Un instrumento para la promoción y la difusión de la investigación de excelencia española. Gaceta Sanitaria, 26(5), 393-394.

Demotes-Mainard, J. \& Ohmann, C. (2005). European Clinical Research Infrastructures Network: promoting harmonisation and quality in European clinical research. The Lancet, 365(9454), 107-108.

Díaz-Faes, A.A.; Benito García, N.; Martín Rodero, H.; \& Vicente Villardón, J.L. (2011). Propuesta de aplicabilidad del método multivariante gráfico Biplot a los estudios bibliométricos en biomedicina. In: Actas XIV Jornadas Nacionales de Información y Documentación en Ciencias de la Salud, p. 66. Cádiz, España: Biblioteca Virtual del Sistema Sanitario Público de Andalucía. Available from http://hdl.handle.net/10760/15998.

Díaz-Faes, A.A., González-Albo, B., Galindo, M.P., \& Bordons, M. (2013). HJ-Biplot como herramienta de inspección de matrices de datos bibliométricos. Revista Española de Documentación Científica, 36(1), e001, doi: http://dx.doi.org/10.3989/redc.2013.1.988.

Fanaroff, A.A.; Hack, M. \& Walsh, M.C. (2003). The NICHD Neonatal Research Network: Changes in Practice and Outcomes During the First 15 Years. Seminars in Perinatology, 27(4), 281-287.

Fernández, M.F; Sunyer, J.; Grimalt, J.; Rebagliato, M.; Ballester, F.; Ibarluzea, J.; Ribas-Fito, N.; Tardón, A.; Fernández-Patier, R.; Torrent, M. \& Olea, N. (2007). The Spanish Environment and Childhood Research Network (INMA study). International Journal of Hygiene and Environmental Health, 210(3), 491-493. 
This is a postprint version of:

Morillo, F.; Díaz-Faes, A. A; González-Albo, B. \& Moreno, L. (2014). Do networking centres perform better? An

exploratory analysis in Psychiatry and Gastroenterology/Hepatology in Spain. Scientometrics, 98 (2), $1401-1416$.

The final publication is available at Springer via http://dx.doi.org/10.1007/s11192-013-1183-5

Font, D.; Gomis, R.; Trilla, A.; Bigorra, J.; Piqué, J.M. \& Rodés, J. (2008). Organización y modelo de funcionamiento de las estructuras de investigación biomédica. Situación y retos de futuro. Medicina Clínica, 130(13), 510-516.

Franceschet, M. \& Costantini A. (2010). The effect of scholar collaboration on impact and quality of academic papers. Journal of Informetrics, 4(4), 540-553.

Gabriel, K.R. (1971). The biplot graphic display of matrices with application to principal component analysis. Biometrika, 58(3), 453467.

Galindo, M.P. (1986). Una alternativa de representación simultánea: HJ Biplot. Qüestioó, 10(1), 1323.

Garner, J.; Porter, A.L.; Newman, N.C. \& Crowl, T.A. (2012). Assessing Research Network and Disciplinary Engagement Changes Induced by an NSF Program. Research Evaluation, 21(2), 89-104.

Ibáñez, A.; Bielza, C. \& Larrañaga, P. (2013). Relationship among research collaboration, number of documents and number of citations: a case study in Spanish computer science production in 2000-2009. Scientometrics, 95(2), 689-716.

Laudel , G. (2002). What do we measure by co-authorships? Research Evaluation, 11(1), 3-15.

Liao, C.H. (2011). How to improve research quality? Examining the impacts of collaboration intensity and member diversity in collaboration networks. Scientometrics, 86(3), 747-761.

Méndez Vásquez, R.I.; Suñén Pinyol, E.; Olivé Vázquez, G.; Cervelló González, R. \& Camí, J. (2009, March). Caracterización bibliométrica de la producción en Epidemiología y Salud Pública (EPI-SP) de España, 19972006. Barcelona. Retrieved from http://bac.fundaciorecerca.cat/ciberesp/docs/Bibliometria CIBERESP.pdf.

Morillo, F. \& Aparicio, J. (2011). Características y disparidades entre sub-especialidades: un estudio de caso con grupos de Biotecnología. Revista Española de Documentación Científica, 34(4), 563-580.

Morillo, F.; Santabárbara, I. \& Aparicio, J. (2013). The automatic normalisation challenge: detailed addresses identification. Scientometrics, 95(3), 953-966, doi: 10.1007/s11192-013-0965-0.

Rank, D. \& Williams, D. (1999). Partial benefit/cost in the evaluation of the Canadian Networks of Centres of Excellence. Evaluation and Program Planning, 22(1), 121-129.

Valderrama-Zurián, J. C.; González-Alcaide, G.; Valderrama-Zurián, F.; Aleixandre-Benavent, R., \& MiguelDasit, A. (2007). Redes de coautorías y colaboración institucional en REVISTA ESPAÑOLA DE CARDIOLOGÍA. Revista Española de Cardiología, 60(2), 117-130.

Vicente Villardón, J.L. (2010). Multbiplot: a packaged for multivariate analysis using Biplots. Departamento de Estadística, Universidad de Salamanca. (Version 1.0) [Software]. Available from http://biplot.dep.usal.es/classicalbiplot/.

Woolf, S.H. (2008). The Meaning of Translational Research and Why It Matters. The Journal of the American Medical Association, 299(2), 211-213. 
This is a postprint version of:

Morillo, F.; Díaz-Faes, A. A; González-Albo, B. \& Moreno, L. (2014). Do networking centres perform better? An

exploratory analysis in Psychiatry and Gastroenterology/Hepatology in Spain. Scientometrics, 98 (2), 1401-1416.

The final publication is available at Springer via http://dx.doi.org/10.1007/s11192-013-1183-5

\section{Appendix}

Table A 1 Relative contributions of the factor to the element for variables (two sets in Psychiatry)

\begin{tabular}{llrrrr}
\hline & \multicolumn{1}{c}{ Variable } & Axis 1 & Axis 2 & Axis 3 & Axis 4 \\
\hline Int & \% Only international collaboration & 123 & $\mathbf{2 6 2}$ & $\mathbf{4 5 9}$ & 9 \\
Natlnt & \% National \& international collaboration & $\mathbf{3 0 8}$ & 211 & $\mathbf{3 6 6}$ & 60 \\
Nat & \% Only national collaboration & $\mathbf{3 8 8}$ & $\mathbf{5 4 2}$ & 1 & 3 \\
Auth & Average number of authors & $\mathbf{3 9 6}$ & 166 & 181 & 0 \\
NoCit & \% Non-cited articles & 156 & 127 & 179 & $\mathbf{5 3 2}$ \\
IF & Average impact factor & $\mathbf{7 1 0}$ & 120 & 2 & 46 \\
Q1 & \% Articles in the first quartile & $\mathbf{6 0 6}$ & 69 & 50 & 111 \\
\hline
\end{tabular}

Table A 2 Relative contributions of the factor to the element for variables (two sets in Gastroenterology/Hepatology)

\begin{tabular}{llrrrr}
\hline & \multicolumn{1}{c}{ Variable } & Axis 1 & Axis 2 & Axis 3 & Axis 4 \\
\hline Int & \% Only international collaboration & 31 & $\mathbf{5 4 9}$ & 187 & 204 \\
NatInt & \% National \& international collaboration & 475 & 52 & $\mathbf{4 0 5}$ & 18 \\
Nat & \% Only national collaboration & 218 & $\mathbf{6 4 4}$ & 69 & 2 \\
Auth & Average number of authors & 110 & $\mathbf{3 1 9}$ & 88 & $\mathbf{4 7 8}$ \\
NoCit & \% Non-cited articles & $\mathbf{5 4 8}$ & 29 & 120 & 7 \\
IF & Average impact factor & $\mathbf{7 7 9}$ & 31 & 34 & 7 \\
Q1 & \% Articles in the first quartile & $\mathbf{7 9 1}$ & 47 & 34 & 12 \\
\hline
\end{tabular}

Table A 3 Relative contributions of the factor to the element for variables for the CIBER set in Psychiatry

\begin{tabular}{llrrr}
\hline & \multicolumn{1}{c}{ Variable } & Axis 1 & Axis 2 & Axis 3 \\
\hline Int & \% Only international collaboration & 20 & 132 & $\mathbf{7 0 6}$ \\
Natlnt & \% National \& international collaboration & 2 & $\mathbf{8 3 4}$ & 109 \\
Nat & \% Only national collaboration & 15 & $\mathbf{9 3 3}$ & 5 \\
Auth & Average number of authors & $\mathbf{3 8 2}$ & 45 & $\mathbf{1 9 6}$ \\
NoCit & \% Non-cited articles & 667 & 1 & 0 \\
Q1 & \% Articles in the first quartile & 650 & 1 & 61 \\
NP & Average normalised position & $\mathbf{8 4 8}$ & 7 & 36 \\
\hline
\end{tabular}

Table A 4 Relative contributions of the factor to the element for variables for the CIBER set in Gastroenterology/Hepatology

\begin{tabular}{llrrr}
\hline & \multicolumn{1}{c}{ Variable } & Axis 1 & Axis 2 & Axis 3 \\
\hline Int & \% Only international collaboration & 64 & $\mathbf{4 7 1}$ & $\mathbf{3 8 9}$ \\
Natlnt & \% National \& international collaboration & $\mathbf{5 1 3}$ & 132 & $\mathbf{3 3 0}$ \\
Nat & \% Only national collaboration & $\mathbf{4 6 3}$ & $\mathbf{4 5 6}$ & 41 \\
Auth & Average number of authors & 112 & 600 & 2 \\
NoCit & \% Non-cited articles & 694 & 65 & 42 \\
Q1 & \% Articles in the first quartile & $\mathbf{8 3 2}$ & 67 & 15 \\
NP & Average normalised position & $\mathbf{7 7 9}$ & 44 & 19 \\
\hline
\end{tabular}

